
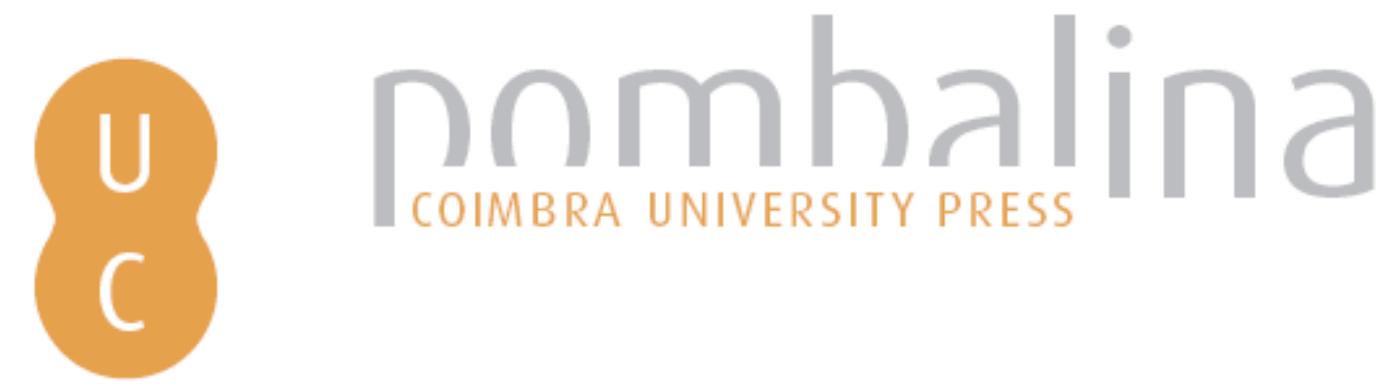

\title{
Regímenes de vida personalizados para las élites eclesiásticas castellanas a finales del siglo XVI: el caso del cardenal Rodrigo de Castro
}
Autor(es):
Serrano Larráyoz, Fernando
Publicado por: Imprensa da Universidade de Coimbra; Annablume
URL
persistente:
URI:http://hdl.handle.net/10316.2/39647
DOI:
DOI:https://doi.org/10.14195/978-989-26-1191-4_18
Accessed : $\quad$ 26-Apr-2023 10:36:40

A navegação consulta e descarregamento dos títulos inseridos nas Bibliotecas Digitais UC Digitalis, UC Pombalina e UC Impactum, pressupõem a aceitação plena e sem reservas dos Termos e Condições de Uso destas Bibliotecas Digitais, disponíveis em https://digitalis.uc.pt/pt-pt/termos.

Conforme exposto nos referidos Termos e Condições de Uso, o descarregamento de títulos de acesso restrito requer uma licença válida de autorização devendo o utilizador aceder ao(s) documento(s) a partir de um endereço de IP da instituição detentora da supramencionada licença.

Ao utilizador é apenas permitido o descarregamento para uso pessoal, pelo que o emprego do(s) título(s) descarregado(s) para outro fim, designadamente comercial, carece de autorização do respetivo autor ou editor da obra.

Na medida em que todas as obras da UC Digitalis se encontram protegidas pelo Código do Direito de Autor e Direitos Conexos e demais legislação aplicável, toda a cópia, parcial ou total, deste documento, nos casos em que é legalmente admitida, deverá conter ou fazer-se acompanhar por este aviso.

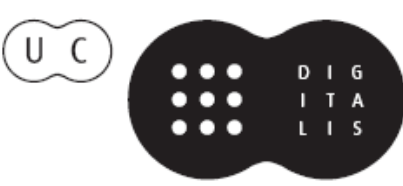




\title{
REgíMENES DE VIDA PERSONALIZADOS PARA LAS ÉLITES ECLESIÁSTICAS CASTELLANAS A FINALES DEL SIGLO XVI: el caso del cardenal Rodrigo de Castro* Personalized Diets for Castillian Ecclesiastical Elites at the End of the Sixteenth Century: The Case of Cardinal Rodrigo de Castro
}

\author{
Fernando Serrano Larráyoz \\ Universidad de Alcalá (fernando.serranol@uah.es)
}

\begin{abstract}
Resumen: En este trabajo se analiza y transcribe un régimen de vida o consilium destinado al cardenal Rodrigo de Castro, fechado a finales del siglo XVI y conservado en la Biblioteca Nacional de España (Madrid). Un ejemplo que muestra el interés de médicos y pacientes por textos que buscan tratar patologías individuales con el fin de procurar la recuperación del enfermo, pero también mostrar como deben ser tratados los casos semejantes al descrito. Un género de la literatura médica hasta ahora poco estudiado para la España renacentista. El caso expuesto es una muestra del aprecio entre las clases altas por la posesión de recursos terapéuticos adaptados a las necesidades individuales, que se copiaban y recopilaban para uso personal.

Palabras clave: Regímenes de vida personalizados o consilia, Rodrigo de Castro, Castilla, siglo XVI.
\end{abstract}

AвSTRACT: This work analyses and transcribes a health regime or consilium made for Cardinal Rodrigo de Castro, dated by the end of 16th century and preserved in the National Library of Spain (Madrid). It serves as an example of how physicians were interested in texts whose purpose was the treatment of individual pathologies, not only in order to cure patients but also as a way of showing how to treat similar cases. This is a genre of medical literature scarcely studied for the Spanish Renaissance. The case displayed shows that the upper classes appreciated the value of therapeutic resources adapted to their individual needs, which were usually copied and compiled for a personal use.

Keywords: Personalized health regimes or consilia, Rodrigo de Castro, Castille, 16th century.

\section{INTRODUCCIÓN}

La proliferación de los regimina sanitatis durante el Renacimiento resulta incuestionable en la literatura médica hispana por la cantidad

* Este trabajo ha sido realizado en el marco de los proyectos de investigación FFI201129117- C02-01 (2012-2015) y FFI2014-53050- C5-3- P (2015-2018) del Ministerio de Economía y Competitividad (MINECO) del Gobierno de España, cofinanciados con fondos FEDER de la Unión Europea. 
de tratados publicados a lo largo del siglo XVI tanto en latín como en romance (especialmente en castellano), y las reediciones de antiguos textos medievales ${ }^{1}$. Una literatura cuyos antecedentes hay que buscarlos en la tradición médica hipocrático-galénica recuperada en la Edad Media y plenamente vigente, que ponía especial énfasis en las denominadas sex res non naturales, factores que si bien no constituían la naturaleza individual de cada persona, como las res naturales (elementos naturales del cuerpo - humores, tejidos y órganos-y sus funciones orgánicas), por ser causa externa de enfermedades también contribuían a un mejor mantenimiento de la salud: es el caso del 'aire y ambiente', el 'ejercicio y descanso', la 'comida y bebida', el 'sueño y vigilia', las 'excreciones y secreciones' y los 'accidentes del alma o del ánimo'. Conocimientos que se difunden a través de las lenguas vernáculas y que reflejan la vigencia de la tradición medieval entre las élites por lo menos hasta el cambio de paradigma científico, en el siglo XIX².

Este trabajo quiere dar a conocer un régimen de vida personalizado de finales del siglo XVI, hoy conservado en la Biblioteca Nacional de España (Madrid). Un documento que muestra el interés de los médicos castellanos por la práctica de la dietética (entendiendo dieta como régimen general de la vida del individuo), así como por sus pacientes, con el fin de lograr el restablecimiento de la salud frente a la enfermedad, un hecho constatado al menos desde la Baja Edad Media33. La disposición de unos y otros por personalizar los regímenes de sanidad editados, mediante la copia y el intercambio de recetas conocidas y previamente experimentadas, el deseo

${ }^{1}$ Sobre la importancia de las lenguas vernáculas en este tipo de obras, véase Gutiérrez Rodi1la 2009: 39. Respecto a la difusión de este tipo de obras en catalán, véase Cifuentes i Comamala 2006: 96-105. Uno de los textos más difundidos en latín, editado a finales del siglo XVI, fue el De regimine cibi atque potus, del portugués Enrique Jorge Enriques (Sanchez-Moscoso Hermida 1982: 219-231). Libro dedicado al archiduque de Austria, cardenal Alberto de Habsburgo (1559-1621), quien fue gobernador de Portugal (1583-1594), Inquisidor General de Portugal (1586-1596?) y arzobispo de Toledo (1594-1598) entre otros cargos. La dedicatoria está datada en 1584, diez años antes de que el libro fuera publicado (Arrizabalaga 1996: 70-71).

${ }^{2}$ Una visión de conjunto sobre la vernacularización y la continuidad de la tradición de la ciencia medieval durante el Renacimiento, véase Cifuentes i Comamala 2008: 123-148.

${ }^{3}$ Respecto a este tipo de textos en la Castilla bajomedieval, véase García Ballester 2001: 357-360. La medicina practicada en el Medievo y en el primer Renacimiento era especialmente individualizada, pero dentro de un concepto de salud universalista. Para lograr la salud de uno u otro órgano o de una persona en particular primero había que analizar su complexión correspondiente, lo que implicaba la existencia de «muchas saludes diferentes» en un mismo individuo. Así las distintas complexiones de cada persona justificaban a su vez la existencia de diferentes regímenes de salud, "reglas de vida individuales hechas a la medida del sujeto que las utiliza, con el fin de mantenerle sano" (Gil-Sotres 1996: 478). Sobre la proliferación de los textos de uso individual en el siglo XVI, consúltese también Solomon 2010: 4. Recientemente se han publicado cuatro prescripciones dietéticas destinadas a miembros de las élites navarras, fechadas las mismas en torno a la primera mitad del siglo XVI, en Serrano Larráyoz 2014: 169-192. 
de poseer recetarios, impresos o manuscritos, contribuye a la proliferación de tratamientos individualizados como el que aquí que se estudia ${ }^{4}$.

La importancia de este tipo de tratamientos se basa en la dificultad de ajustarlos, dentro de un género literario, los regimina sanitatis ${ }^{5}$. Mientras los regimina son considerados textos doctrinales amplios que hacen un recorrido completo y ordenado por las 'seis cosas no naturales', el documento que presentamos aparece como un conjunto de consejos plenamente personalizados, a manera de prescripción para un paciente concreto o consilia. En general están escritos según el modelo epistolar y divididos en tres apartados: primero el casus, donde el médico trata una enfermedad de un paciente en particular; a veces se ofrecen algunos detalles, como el nombre, edad y en ocasiones los síntomas de la enfermedad. Sigue el apartado de la dieta con recomendaciones de naturaleza higiénica - con una sección dedicada a los alimentos generalmente bastante desarrollada -, para terminar con la cura basada en una farmacopea en particular ${ }^{6}$. Destaca en nuestro caso la amplia disertación del médico que intenta explicar el origen y causas de la enfermedad que pretende tratar; responde a un problema clínico de su cliente, que trata de curar con la ayuda de un régimen de vida específico, bastante focalizado en modelos de carácter dietético?

\section{UN RÉGIMEN DE VIDA O CONSILIUM PARA EL CARDENAL RODRIGO DE Castro (I 523 - i6oo)}

Rodrigo de Castro Osorio nació en Valladolid en marzo de 1523. Undécimo hijo de Beatriz de Castro, tercera condesa de Lemos, en su matrimonio con el conde Álvaro de Osorio, el futuro cardenal pasó la mayor parte de su infancia en Monforte de Lemos (Lugo). En 1541 inició estudios de Derecho Canónico en Salamanca, donde se graduó en julio de 1552. Recibió la consagración sacerdotal tal vez de Pedro de Castro, su hermano uterino, obispo de Cuenca. Desde finales de abril de 1558 la Iglesia española se había visto sacudida por la detención inquisitorial del arzobispo de Toledo,

${ }^{4}$ En el testamento, fechado el 12 de agosto de 1598, el paciente, el cardenal Rodrigo de Castro, reconoce poseer libros de "teología como de cánones, de Leyes, Historia y medicina" (Cotarelo Valledor 1946: 332).

${ }^{5}$ Durante los periodos medieval y renacentista la dietética forma parte de la enseñanza de la medicina práctica, junto con la farmacopea y la cirugía, para el tratamiento de las enfermedades. La define en su doble sentido el término latino diaeta. Palabra que en sentido estricto se refiere a la comida y la bebida y en sentido amplio a las 'cosas no naturales'. A diferencia por tanto de la farmacopea o de la cirugía, la dieta se utilizaba como cura y a la vez como medio para prevenir las enfermedades y conservar la salud (Nicoud 2010: 16).

${ }^{6}$ Nicoud 2007: 314-315. Sobre la evolución de los consilia durante el periodo medieval y renacentista, en Laín Entralgo 1998: 68-136.

${ }^{7}$ Sobre algunas de estas cuestiones, véase Cabré 2011: 169-173. 
Bartolomé de Carranza, en cuyo proceso, hasta 1565, estuvo involucrado Rodrigo de Castro en varias de las etapas tanto en España como en Roma. Obispo de Zamora (1574-1578), de Cuenca (1578-1581), arzobispo de Sevilla en octubre de 1581, es nombrado cardenal por el papa Gregorio XIII en diciembre de 1583. Al servicio de Felipe II, el rey le encomienda misiones de relevancia, como la defensa de sus derechos al trono portugués. Entra en el Consejo de Estado en 1596, cargo que mantendrá en el reinado de Felipe III, y en el de la Inquisición. Fallece en la ciudad de Sevilla el 18 de septiembre de $1600^{8}$.

El "regimiento" cuya transcripción presentamos está localizado en un manuscrito cuyo título general es Papeles varios de física, química y medicina, donde se recogen textos de diversa índole escritos en latín, italiano y español ${ }^{9}$. Poco sabemos sobre su fecha de redacción, quizá lo fuera entre 1583 y 1600, años entre su acceso al cardenalato y su muerte. Desconocemos el autor de dicho texto, si bien por las reflexiones que en él se hacen parece un médico helenista de excelente formación, quizá alguno de los médicos de cámara del propio arzobispo en su estancia en Sevilla ${ }^{10}$. Cualquiera que fuera el autor, tiene este un conocimiento fluido del griego y el latín, cita a Galeno e Hipócrates, a quienes sigue principalmente en su explicación de la enfermedad del cardenal, y a Eliano ${ }^{11}$, Aristóteles ${ }^{12}$ y Platón ${ }^{13}$, muchos de ellos, probablemente todos, aludidos, como en el caso de Anaxágoras, a través de obras médicas coetáneas. Del mismo modo el autor está al tanto de la nueva anatomía que tras la obra de Andrea Vesalio (De bumani corporis fabrica) se había extendido por toda Europa en la segunda mitad del siglo XVI. El autor

\footnotetext{
${ }^{8}$ Sobre su biografía, véase Cotarelo Valledor 1945-1946; Alde Vaquero, Marín Martínez y Vives Gatell (eds.) 1972: 382-384; Rodríguez 1998: 116; y Salas Merino 2014: 62-63. Se conserva una descripción de sus últimos días: "El Illustrísimo y Reverendísimo señor don Rodrigo de Castro, cardenal y arçobispo de Sevilla (...) se començó a sentir indispuesto de un hastío por principio deste mes de septiembre del año presente de Mil y Seiscientos, en quinçe o diez y seis días fue muy poco lo que comió y aunque se yva debilitando nunca se detuvo en la cama, y todos los días se levantó a oyr misa y a rezar las horas, y asistió a los consejos y despachos de los negocios y salió a comer y cenar en público, esforcandose y disimulando contra la fuerça de la enfermedad. Domingo 17 del dicho mes se sentó a comer y luego le siguió un desmayo que le privó del sentido, lleváronle a la cama y de allí a poco bolvió en sí, acudieron los médicos y començaron a aplicarle algunos remedios que todos fueron sin provecho" (RAH-PaJe 9/3669: 334).

${ }^{9}$ BNE-Ms 3355: 301-313.

${ }^{10}$ E1 3 de enero de 1595 el cardenal se refiere a Augusto Ticio, "que al presente reside en la ciudad de Pisa, que vivió muchos años en mi casa haciendo officio de mi médico" (RAH-PaJe 9/3678: 145r). Tras el regreso de este a Italia, parece que le sirvió Juan de Carmona, quien le dedicó un tratado de astrología judiciaria (Cotarelo Valledor 1945: 156 y 328), en el que plantea la cuestión de la astrología como disciplina obligada para los médicos (Carmona 1590).

${ }^{11}$ De varia historia (Apéndice documental, p. 301). Ver nota no 71

${ }^{12}$ De anima (Apéndice documental, p. 301). Ver nota no 81.

${ }^{13}$ In Charmide (Apéndice documental, p. 308). Ver nota no 144.
} 
conoce la existencia de los tres huesos que conforman el tímpano (yunque, martillo y estribo) y "que los anatomistas de nuestros tienpos an hallado", pero no menciona a los autores de su descubrimiento ${ }^{14}$. Igualmente está al corriente de alguna de las obras de Jean Fernel (1485-1558), médico de Enrique II de Francia, que tampoco menciona, si bien alude a una receta de este último para tratar el estreñimiento ${ }^{15}$.

Fiel a la doctrina hipocrática-galénica, el autor propone buscar la "essentia" de lo que su cliente padece y "las causas que lo hacen" con el fin de poner remedio a su enfermedad ${ }^{16}$. De hecho modifica un régimen de vida anterior - "Aviendo pues nosotros de quitar algunas cosas del regimiento de Vuestra Illustrísima i de añedir otras" ${ }^{17}$ - mostrando el carácter dinámico y la continua adaptación que sufrían los regímenes, adecuándose según las incidencias de la salud del enfermo. Escruta algunas causas que pueden provocar el "ruido que siente en la cabeça" su paciente, y concluye que el malestar puede deberse a "flatos o ventosedades" que se mueven dentro de la cabeza ${ }^{18}$. Descarta que la indisposición pueda tener otros motivos, como que una posible "biveza de oído (...) le causase ruido perpetuo" o la "flaqueza", propia de enfermos de largas enfermedades o de aquellos "que an tenido grandes evacuaciones" 19 . Por un lado, sigue la obra de Galeno De compositione pharmacorum secundum locos ${ }^{20}$, donde se citan las causas externas que pueden producir molestias en la cabeza (bien la frialdad bien el ardor, golpes en la propia cabeza, ciertas enfermedades, empachos, borracheras, esfuerzos por intentar vomitar o la utilización de «alguna medicina en el oído»). Por otro, juzga necesario conocer si el ruido se había producido de repente o de forma paulatina, y si lo siente continuadamente ${ }^{21}$. También está al tanto de la obra De morbis oculorum et aurium affectibus praelectiones, a la que alude en una apostilla del texto, de Girolamo Mercuriale (1530-1606) ${ }^{22}$.

${ }^{14}$ Apéndice documental, p. 302. El descubrimiento del estribo se debe al médico valenciano Luis Collado, discípulo de Vesalio (López Piñero, Calero 1988: 195-196).

${ }^{15}$ Apéndice documental, p. 312.

${ }^{16}$ Apéndice documental, p. 301.

${ }^{17}$ Apéndice documental, p. 301.

${ }^{18}$ Apéndice documental, p. 302.

${ }^{19}$ Apéndice documental, p. 303.

${ }^{20}$ Apéndice documental, pp. 303 y 306.

${ }^{21}$ Apéndice documental, p. 304.

${ }^{22}$ Apéndice documental, p. 304 (Mercuriale 1590). Profesor de las universidades de Padua (1569-1587), Bolonia (1587-1592) y Pisa (1592-1606). Escribió más de veinte libros impresos, muchos de ellos derivados de las enseñanzas recogidas por sus estudiantes. Su obra abarca todo tipo de temas, desde la psiquiatría de ginecología, pediatría, dermatología, toxicología, epidemiología, historia de la medicina... (Siriasi 2003: 231-251). 
Una vez aceptado que el origen del ruido procede de gases internos (ventosidades), se exponen, de acuerdo con textos galénicos (De symptomatum causis $^{23}$, Commentarium in primo prorrheticorum Hippocratis ${ }^{24}$, De compositione pharmacorum secundum locos ${ }^{25}$, De methodo medendi $i^{26}$, De locis affectibus ${ }^{27}$ ) e hipocráticos (De victus ratione in morbis acutis ${ }^{28}$ ), los motivos que pueden provocarlos. Sigue igualmente los planteamientos de Galeno, cuando considera los flatos o ventosidades de la cabeza producto de la disminución del "calor natural"29. Flatos que pueden estar motivados por la avanzada edad del paciente o cualquier "otra causa que le oviesse consumido el úmido radical (...) sin que pudiesse recuperarse". Otra opción que apunta es que el calor natural se haya reducido debido al mal funcionamiento de los mecanismos fisiológicos de evacuación. Concluye, de acuerdo con el pulso, el estado de las heces y orina, la movilidad del cardenal y la práctica de sus actividades diarias ("trabajo"), que la pérdida de calor natural es debida a la concurrencia de causas que nada tienen que ver con la naturaleza del paciente (per aggravationem) ${ }^{30}$.

El médico propone entonces la posibilidad de que el ruido que afecta a su paciente se genere en la propia cabeza o se produzca por "vapores que suben del estómago". Ante el buen estado físico de este último se permite rechazar la primera opción ${ }^{31}$. El diagnóstico por tanto está claro: las ventosidades generadas en la cabeza son debidas a una deficiente purgación de los excrementos a través de los órganos excretores y a ciertos vapores que suben a la cabeza desde el estomago. Afirmación que justifica por las molestias que al despertar siente el cardenal, bien que atenuadas con el paso de las horas, señal de que no se ha "evaporado lo que con el sueño ha subido" ${ }_{32}$.

Para devolver el equilibrio al paciente, en sus molestias por la atribuida relación entre estómago y cabeza, recomienda una dieta. Según el autor del texto "es precepto en Medicina no se puede curar la parte sin que primero se cure el todo (...) para esto que no se puede curar el todo sino se cura

${ }^{23}$ Apéndice documental, p. 305. Ver nota no 122.

${ }^{24}$ Apéndice documental, pp. 303 y 306. Ver notas no 103 y 125.

${ }^{25}$ Apéndice documental, p. 306. Ver nota no 129.

${ }^{26}$ Apéndice documental, p. 306. Ver nota no 127.

${ }^{27}$ Apéndice documental, p. 308 . Ver nota no 140

${ }^{28}$ Apéndice documental, pp. 303 y 306. Ver notas no 101 y 133.

${ }^{29}$ La fisiología galénica supone que el organismo viviente posee un grado y cantidad determinados de calor dispuesto en su interior. Este calor natural podía sufrir aumentos y decrecimientos ocasionales, que no se consideraban patológicos ya que pertenecían al desenvolvimiento normal del funcionamiento del cuerpo humano (Moreno Rodríguez 1985-86: 11).

${ }^{30}$ Apéndice documental, pp. 306-307.

${ }^{31}$ Apéndice documental, pp. 307-308. En la parte superior de la página 308 se recoge en una apostilla la cita al capítulo sexto de la obra de Galeno Ad glauconem de medendi methodo libri II (Apéndice documental, p. 308). Ver nota no 26.

${ }^{32}$ Apéndice documental, p. 308. 
primero el alma" ${ }^{33}$. El tratamiento individualizado de Rodrigo de Castro, con más de 60 años por esas fechas, trata por todos los medios de conducir la complexión del anciano hacia la humedad y el calor, cuyo desarrollo queda reflejado en numerosos tratados medievales y renacentistas. La necesidad de consumir alimentos calientes y húmedos - entre los que se incluye el vino - por los pacientes de avanzada edad-de temperamento frío y seco-queda avalada por juzgar que la vejez no es un proceso natural sano sino propio de la enfermedad ${ }^{34}$.

Todos los regímenes de salud de la época son partidarios de la sobriedad en comidas y bebidas. En nuestro caso el médico del cardenal recomienda al enfermo que "tenga moderados apetitos i particularmente temperantia". Ordena para él dos comidas al día, si bien considera la del mediodía como la "principal"; por la noche ha de comer muy poco "i que no sea carne ni pescado" 35 . Comidas y cenas de "pocos manjares i simples que no sean guisados" ${ }^{36}$. La realización de dos comidas diarias era apropiada para personas de complexión seca, acompañadas de un fuerte calor innato, acostumbradas a tomar alimentos sutiles ${ }^{37}$.

Propone que comidas y bebidas ordinarias sean "en calidad de buen mantenimiento, tenplado", con sustancia, pero "ni gruesso, ni viscoso, ni aguanosos"; de ellas excluye las carnes de vaca, cerdo, “venazón”, jabalí, y también el manjar blanco, los manjares de pasta, empanadas y cecinas. De hecho la dietética medieval considera óptimas las carnes de los animales terrestres o cuadrúpedos, siempre que generen humores bien sean sutiles bien gruesos y viscosos. Pese al rechazo por parte de nuestro médico de las carnes de cerdo, venado y jabalí, estas dos últimas eran consideradas como buenas por ciertos tratadistas medievales, caso de Maino de Maineri o Arnau de Vilanova ${ }^{38}$, mientras que en el caso de la de cerdo doméstico, más húmedas

${ }^{33}$ Apéndice documental, p. 308.

${ }^{34}$ Apéndice documental, pp. 309-310 y 313. Gil-Sotres 1996: 489; Cruz Cruz 1997: 116.

${ }^{35}$ Los médicos medievales y renacentistas discrepan sobre la hora de tomar las dos comidas. Arnau de Vilanova se inclina por la tarde para la principal, en contra de Gerardo de Solo y Luis Lobera de Ávila, médico de Carlos V, en su Banquete de nobles caballeros, de 1530, partidarios de la mañana. Lobera exceptúa de este horario a quienes "que ocupados de negocios espirituales, sin exercicio corporal, hacen una breve colación por la mañana en lugar de comida, y a la tarde hacen su cena cumplida" (Gil-Sotres 1996: 654-656; Lobera de Ávila 1996: 51).

${ }^{36}$ Apéndice documental, pp. 308-309.

${ }^{37}$ Gil-Sotres 1996: 656. En unas prescripciones destinadas al veneciano Juan Rena durante la primera mitad del siglo XVI, el almuerzo (comida) y la cena eran consideradas como de obligado cumplimiento. El primero se tomaba en torno a las 10 de la mañana y la segunda entre las 8 y las 9 de la noche (Serrano Larráyoz 2014: 177).

${ }_{38}$ Gerardo de Solo, sin embargo, tiene ciertas cautelas respecto al ciervo (Gil-Sotres 1996: 692). Francisco Núñez de Oria, por su parte, en su Regimiento y aviso de sanidad considera que la carne de los animales domésticos son mejores que la de los «monteses» (1585: 76-80 y 107-108). 
y viscosa, recomiendan su salazón. El repudio de la carne de vaca sigue las pautas médicas de la época, al considerar poco beneficioso el vacuno de más de tres años ${ }^{39}$. La oposición a los manjares de pasta y empanadas también guarda relación con los planteamientos propuestos por Luis Lobera de Ávila, quien considera, siguiendo a Avicena y Galeno, que "todas las cosas de fruta de pasta son dañosas (...) y de mala digestión" ${ }^{40}$. No extraña tampoco la oposición a que el cardenal Castro coma todo tipo de cecinas, puesto que son carnes consideradas secas, por tanto inadecuadas para la complexión de personas de avanzada edad. Quizás sorprenda el rechazo al manjar blanco, una de las preparaciones más características y apreciadas del periodo bajomedieval y renacentista, hecho a base de carne de gallina, harina de arroz, agua rosada, azúcar fino y leche de cabra ${ }^{41}$. La utilización de leche, producto que desde la Antigüedad produjo desconfianza en los médicos por la inestabilidad de su conservación y las alteraciones por el calor, pude contribuir en este modo de pensar $^{42}$. Igualmente desaconseja todos los pescados, salvo excepciones puntuales como las acedías, lenguados, mojarras y truchas frescas, a consumir siempre cocidos y degustar calientes ${ }^{43}$. Su preparación en empanadas es rechazada de plano "porque aunque son malas todas las enpanadas son peores las de pescado" ${ }^{44}$. Una opinión sobre elaboraciones con masa no siempre unánime ${ }^{45}$.

${ }^{39}$ Luis Lobera de Ávila también es contrario al consumo de reses de avanzada edad, si bien con algunas excepciones de acuerdo con los criterios de Isaac Israelí, Avicena y Galeno (Lobera de Ávila 1996: 74).

${ }^{40}$ Lobera de Ávila 1996: 89.

${ }^{41}$ Nola 1999: 83-84.

${ }^{42}$ Los autores medievales establecen sus valoraciones según procedan del norte o del sur de Europa. Sobre esto, véase Gil-Sotres 1996: 701-702. Lobera de Ávila considera que "las cosas de leche, queso, manteca, natas no son buenos manjares, salvo un poco de queso y pocas veces". Afirma que "la leche de los animales gruesos y nuevos, que han pacido buenas hierbas y ha poco que parieron es más templada leche y mejor que de los otros. No es tan dañosa, y máxime, si no mezclan otros manjares con ella, será buena; y si es al contrario desta hace contrarias operaciones" (Lobera de Ávila 1996: 150). Sobre las virtudes de la leche "si se toma en estómago y cuerpo limpio de malos humores", sus variedades, sobre lo que hay que hacer tras su consumo y sus derivados o los daños que provoca la ingesta continuada y su forma de preparación, en Núñez de Oria 1585: 155-162.

${ }^{43}$ Apéndice documental, p. 309. Por regla general los tratadistas medievales desaconsejan el consumo de los peces de fácil adquisición. Mientras que recomiendan las especies más caras y de difícil consecución. Un ejemplo de lo que se entendía el prestigio de lo escaso y caro, muy en relación con la posición social de quien lo consume (Gil-Sotres 1996: 697). Tres de los cuatro pescados aludidos en el "régimen" para el cardenal Castro son considerados como no "tan dañosos como otros, y en algunas tierras, los dan a los enfermos por pescados muy sanos" (Lobera de Ávila 1996: 85). La trucha, pese a ser un pescado de agua dulce, suele ser aceptada por los médicos casi sin excepción (Serrano Larráyoz 2014: 179 y 184). Las variedades procedentes de lagunas y estanques cerrados son desaconsejadas porque "no se pueden mantener sino de cieno y barro, y suciedad" (Núñez de Oria 1585: 172v).

${ }^{44}$ Apéndice documental, p. 309.

${ }^{45}$ Gil-Sotres 1996: 699; Serrano Larráyoz 2014: 178. 
Por el contrario recomienda el consumo de carnes de gallina, pollo, capón, perdiz, gazapo, cabrito, carnero y ternera, acorde con los regímenes conocidos y algunas prescripciones dietéticas de la época ${ }^{46}$.

En cuanto a las frutas, el "regimiento" no pone objeción a las de invierno salvo al melón ${ }^{47}$. Se sugiere no consumir las de verano, con alguna ciruela de manera excepcional, unas pocas uvas "después de aver estado colgadas algunos días", y peras o membrillo "por postre" ${ }^{48}$. Se rechazan las frutas veraniegas por la creencia de que provocan un aumento del calor y de la sequedad, con inevitable repercusión sobre los humores ${ }^{49}$.

Es de sobra conocida la consideración del vino como bebida y a la vez alimento por los médicos galénicos. El vino que se prescribe de forma habitual es el ligero, algo aguado, para que no "tenga fuerça de vino". Los caldos sevillanos son rechazados por la gran cantidad de yeso que se les agrega y algunos otros por el "mosto que les echan". El mejor considerado de todos ellos es el de Ciudad Real ${ }^{50}$. Sobre el agua de invierno destaca como la "mejor desta tierra" la de Fuente del Algarrobo ${ }^{51}$, según la creencia médica de considerar el agua de las fuentes como la más adecuada para consumo humano. A la hora de ser bebida y para añadir agua al vino se aconseja su cocción con una pequeña cantidad de raíz de la China o canela ${ }^{52}$. La temperatura del brebaje será fresca, sin enfriarla con nieve, tal y como lo recomiendan

${ }^{46}$ Gil-Sotres 1996: 692-694; Lobera de Ávila 1996: 73-76; Serrano Larráyoz 2014: 178 y 183.

${ }^{47}$ Actualmente la gran mayoría de las variedades de melones se recolectan, dependiendo de los lugares, entre junio y septiembre. Algunas otras se recogen en invierno, con unas características más acusadas, como una corteza más dura, el aroma más suave, y un periodo de maduración más largo.

48 Apéndice documental, p. 309. Según Avicena la uva pasa "es amiga del hígado y del estómago" (Núñez de Oria 1586: 265r).

${ }^{49}$ Gil-Sotres 1996: 686. Luis Lobera de Ávila, en principio, no tiene una idea peyorativa del consumo de las distintas variedades de melones, si bien refleja en su tratado las reticencias de Avicena a esta fruta. Por el contrario, sus valoraciones sobre las ciruelas, las uvas, las peras y los membrillos son generalmente positivas, en especial de las segundas, que en voz de Alberto Magno "las uvas cogidas a mediodía en luna menguante, siendo día claro y uvas de buena nación, estando colgadas tres o cuatro días antes de que se coman, son buenas" (Lobera de Ávila 1996: 141-142, 101, 95,113,115). Una reflexión negativa sobre el consumo general de la fruta, en Núñez de Oria 1585: 229v-236r.

${ }^{50}$ Lobera destaca los vinos blancos de Ciudad Real junto los de Ribadavia, Yepes, Madrigal, Simancas, Medina del Campo, Valladolid y otros que "no siendo adobados, son medicinales" (Lobera de Ávila 1996: 63)

${ }^{51}$ En el casco urbano del municipio de Gelves, en la provincia de Sevilla, se localiza una fuente con el nombre de Fuente del Algarrobo a cuya agua se le atribuyen propiedades medicinales (http://www.conocetusfuentes.com/ficha_detalle.php?id_fuente=2244) (Universidad de Granada).

${ }^{52}$ La raíz de la China hace alusión a alguna variedad del género Smilax, todas ellas de propiedades purgativas. La canela, de olor suave, se consideraba aromatizante y que confortaba el estómago frío y húmedo; se utilizaba para los dolores coléricos y ventosos (Cruz Cruz 1997: 177). 
algunos tratadistas árabes o Bernardo de Gordon ${ }^{53}$. Según el pensamiento médico del momento, cuanto más húmedos y sutiles fueran los alimentos menor sería la necesidad de bebida. Acorde con este criterio, se aconseja al cardenal Castro que no beba entre horas y que ingiera "la menos cantidad que fuere posible" en la comida principal y cena ${ }^{54}$.

Otro de los aspectos del cuidado de la salud (higiene) está basado en la práctica del ejercicio. Se considera el ejercicio como el movimiento voluntario de algunas partes del cuerpo, que origina modificaciones saludables en quien lo efectúa. Según el médico del cardenal, el ejercicio mejoraba su indisposición y también le servía "para preservarse de otras muchas" dolencias. Recomienda su práctica en ayunas, "porque después de comer es causa de muchos males", y evacuar con anterioridad, de acuerdo con la doctrina fisiopatológica galénica de que el ejercicio refuerza el calor natural, lo que facilita el proceso digestivo en los miembros, estómago, hígado y venas. E1 ejercicio realizado antes de comer, una vez evacuadas las superfluidades de la primera o segunda digestión (orina y heces), preparaba al estómago para la recepción del alimento en prefectas condiciones de funcionamiento ${ }^{55}$.

La rutina del ejercicio debía realizarse de forma moderada a fin de entrar en calor, "pero que no llegue a cansarse"; es decir, buscando la satisfacción personal y la tonificación de los miembros ${ }^{56}$. Considera las mejores condiciones ambientales cuando el aire está "limpio de nieblas i de toda unidad" y sin corrientes de aires "rezios i delgados" que perjudiquen al paciente ${ }^{57}$. Con todo, el galeno del cardenal es consciente de las muchas ocupaciones que su paciente ha de atender a diario y las dificultades que esto supone para realizar ejercicios con regularidad. Por ello alaba los beneficios del ejercicio en actividades campestres o lúdicas, más incluso que su práctica "por solo la salud". Le propone como actividades la equitación, junto con paseos a pie y "en litera" ${ }_{58}$. No se le escapan al médico los rigores del invierno para poder

${ }^{53}$ Gil-Sotres 1996: 712. Francisco Núñez de Oria considera que quienes echan nieve dentro de la bebida "tragan la muerte dulce, y si no lo sintieren de presente, sentirlo han si lo acostumbran adelante, no después de muchos meses" (1585: 323r).

${ }^{54}$ Apéndice documental, p. 310. Lobera explicita que "al comer y al cenar ha de tener esta orden: que no ha de beber hasta que haya bien començado a comer, y hace de beber menos que comer, porque el mucho beber corrompe la digestión y encharca el estómago, y hace pasar el manjar sin perfecta digestión a los otros miembros y hace otros daños". Alude asimismo a Avicena y Rhazes como autoridades en las que justificar que «el agua que se bebiere a la mesa ha de ser fría e no enfriada a la nieve, ni agua de nieve» (Lobera de Âvila 1996: 53-54).

${ }^{55}$ Apéndice documental, p. 310; Cruz Cruz 1997: 91-93.

${ }^{56}$ Cruz Cruz, 1997: 94.

${ }^{57}$ Sobre las características para que el aire sea considerado puro y, por tanto, beneficioso para el organismo, Gil-Sotres 1996: 574-580.

${ }^{58}$ Los médicos latinos consideran el andar como el ejercicio más sencillo y por tanto el más aconsejable. A quienes pertenecían a las clases sociales privilegiadas queda reservada la 
seguir estas recomendaciones. Así, en los días que no fuera posible el ejercicio, lo supliría con masajes (fregamientos y frotamientos) corporales: primero con un paño "algo asperillo" y después con aceite de almendras dulces. Práctica esta última que sirve para eliminar los residuos de la tercera digestión que los miembros del cuerpo realizan, además de aumentar el calor natural y de endurecer o ablandar los músculos. Con el fin de fundamentar su propuesta de masajes con friegas de aceite de almendras el médico del cardenal alude al uso de este aceite en las comidas por el papa Pablo III (1534-1549), "que fue muy atento a la conservación de su salud" ${ }^{9}$.

Durante las cuatro horas siguientes a la ingesta de alimentos desaconseja la lectura, la escritura y todos los "negocios de entendimiento". Tal es el perjuicio que puede provocar esta rutina que se sugiere al cardenal rezar antes de cenar y no hacerlo en horas posteriores ${ }^{60}$.

Entre las cosas no naturales relacionadas con la recuperación de la salud (o su mantenimiento) está el binomio del sueño y la vigilia. Sobre los beneficios funcionales del sueño divergen los autores, ajustando las recomendaciones generales con el fin de que sus acciones benéficas fueran aprovechadas al máximo. Sin proponer un tiempo determinado para el descanso, considera suficiente el que "por experiencia tiene" y le es necesario ${ }^{61}$. La rutina ha de acompañar la vida diaria del cardenal, salvo que motivos de salud le obliguen a posponer la hora de acostarse o adelantar el levantamiento por la mañana ${ }^{62}$. No se considera saludable la práctica de la siesta si ha descansado lo suficiente la noche anterior ${ }^{63}$.

La eliminación de los restos producidos en la primera digestión, la ocasionada en el estómago, es una de los hábitos privados sobre los que advierten repetidamente los médicos, por otro lado actividad rutinaria indispensable para conseguir los resultados deseados. Las prescripciones son claras: al paciente se le insta "hazer de cámara" por la mañana y por la noche, debiendo acostumbrar al cuerpo a "entretenerse en la expulssión de flatos". Para el estreñimiento, la tratadística antigua proporciona remedios tales como el consumo de higos,

práctica de la equitación, mientras que Avicena considera como ejercicio el ser porteado sentado o acostado (Gil-Sotres 1996: 619-622).

${ }^{59}$ Apéndice documental, pp. 310-311. Sobre el ejercicio y los masajes, Gil-Sotres 1996: 599- 629. Respecto al "exercicio que ha de hacer antes de comer y cenar y sus provechos", Lobera de Ávila 1996: 41-42.

${ }^{60}$ Apéndice documental, p. 311.

${ }_{61}$ Afirma Lobera que "se ha de dormir según la calidad de las personas y costumbre" (Lobera de Ávila 1996: 55).

${ }_{62}$ Apéndice documental, pp. 311-312. Sobre el sueño, véase Gil-Sotres 1996: 735-752.

${ }^{63}$ Lobera también se muestra contrario a dormir después de comer, atribuyendo a esta costumbre el origen de enfermedades como el dolor de cabeza entre otras. Si no queda más remedio propone realizarla media hora después de comer, "floxa la cinta y los çapatos quitados y cubiertos los pies, y la cabeça alta”. La siesta debe ser corta y en lugar oscuro (Lobera de Ávila 1996: 49). 
uvas pasas o pan con salvado. En esta ocasión la recomendación estriba en la toma de aceite común o hervido con manzanilla ${ }^{64}$.

La evacuación de las heces se considera primordial para tratar la afección del noble cardenal, en caso de no conseguirlo se propone el uso de unas píldoras, a base de almáciga, sacadas de una receta del francés Jean Fernel. Utilización y cantidad conforme a la necesidad y que tomará en torno a las 11 de la noche, "antes de dormir, aviendo cenado temprano i menos que lo ordinario" ${ }^{65}$.

Finalizan las prescripciones instando al cardenal a que todas las mañanas, una vez hechas sus necesidades, se peine y se lave la cabeza "con algún lienço áspero". Se le exhorta también a mantener limpios tanto los canales auditivos como los olfativos, además de los pulmones. La práctica del aseo le servirá para eliminar los desechos procedentes de la tercera digestión, consistente en la asimilación por los miembros, de los materiales nutritivos aportados por la sangre ${ }^{66}$. Para favorecer la expulsión de mocos se recomienda el uso de "alguna aguamiel sorvida por las narizes”. Así, una vez conseguida la evacuación de las ventosidades que afectan al cardenal, nuestro médico rechaza utilizar "remedios fuertes" dentro del oído, alegando el peligro de ensordecer que tienen "semejantes medicinas" ${ }^{67}$. No rehúsa, si embargo, proponer algún vaho "de cocimiento hecho en vinagre" a base de algunas hierbas (manzanilla, ruda, eneldo, cantueso, hinojo, comino y anís) si las molestias persisten. El vapor debía introducirse en el oído, previamente cubierto con algodones «que tuviesen algalia», a través de un canuto. Tras la toma del vapor se recomienda tapar el oído con algodones con almizcle, mojados en aguardiente, "o usar de los saquillos de ciprés que Vuestra Ilustrísima suele usar”"68, probablemente colgados del pecho.

\section{REFLEXIONES FinAles}

E1 valor del documento que se estudia y transcribe en el presente trabajo queda reflejado por su utilidad para conocer la práctica real de los

${ }^{64}$ Apéndice documental,p. 312. Sobre la eliminación de las heces, Gil-Sotres 1996: 754-757. La manzanilla se utilizaba en medicina como purgante estomacal (Serrano Larráyoz 2015: 80).

${ }^{65}$ Apéndice documental, p. 312. Muy bien puede referirse a las pilullae stomachicae qua cibo praemissae ventriculum expurgant... aludidas en su obra póstuma Universia medicina (Fernel 1577: 500).

${ }^{66}$ Las lágrimas de los ojos, los mocos de las narices, los esputos que proceden del pulmón, la cera generada en los oídos, entre otros, debían ser convenientemente eliminados del cuerpo, con el fin de que su acumulación no ocasionara enfermedades que afectaran a la piel y zonas próximas, a alguno de los órganos determinados, o incluso convertirse en enfermedades generalizadas (Gil-Sotres 1996: 757-761).

${ }^{67}$ En el texto se incluye una referencia que alude a la obra de Jacques Houllier, Ad libros Galeni de compositione medicamentorum kata topus Periochae VIII. La primera edición que he localizado es de 1571.

${ }^{68}$ Apéndice documental, pp. 312-313. 
fundamentos teóricos de la medicina universitaria y el galenismo en personajes concretos. Documento que muestra el interés del ámbito médico y de los sectores privilegiados por acomodar e individualizar los conocimientos propios de los manuales especializados en el cuidado de la salud. Se ofrece así una visión personalizada de la enfermedad y su tratamiento, a diferencia de las generalizaciones propias de los regímenes de sanidad divulgados por la imprenta durante el Renacimiento. De hecho, pese a las diferencias que

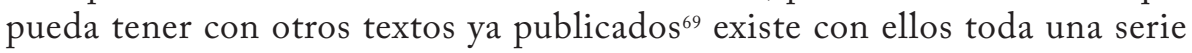
de coincidencias de carácter práctico. La moderación en las comidas y su forma de elaboración, las similares variedades de carnes recomendadas, el recelo a la fruta fresca, junto con el escaso aprecio que suscita el pescado salvo excepciones, la importancia del sueño, de la vigilia y de la expulsión de las excreciones, la práctica de ejercicio, el trabajo moderado o la rutina del aseo son algunos ejemplos.

No hay duda de la utilidad que el presente texto debió de tener para su dueño, quien no era ajeno al interés por la medicina ${ }^{70}$. A reseñar también que la redacción de las prescripciones está en castellano y no en latín, idioma universal del saber europeo hasta ese momento. Particularidad por otra parte nada desdeñable, si tenemos en cuenta de haber sido realizado por un médico culto para un paciente eclesiástico, cuyo conocimiento de la lengua latina por este queda fuera de dudas. Circunstancia que constata la importancia que van adquiriendo las lenguas vulgares en las élites ilustradas a la hora de la trasmisión de los conocimientos médicos. Los pocos párrafos escritos en latín y aun menos en griego, responden a citas literales de autores clásicos que tienden a reforzar los argumentos médicos.

Como en otros casos, se comprueba aquí una perfecta trasposición práctica de lo aconsejado en los tratados médicos doctrinales al uso, y la plena vigencia, a finales del siglo XVI, de la doctrina hipocrático-galénica recuperada en la plena Edad Media. Podemos concluir diciendo que en el caso del cardenal Rodrigo de Castro queda plenamente reflejado el recurso a los principios alopáticos para combatir enfermedades, junto con la recomendación de alimentar a los enfermos con dietas contrarias a las cualidades complexionales propias del cuadro morboso.

\section{Bibliografía Final}

Alde Vaquero, Q., Marín Martínez, T., Vives Gatell, J. (eds.) (I972), Diccionario de Historia Eclesiástica de España, Vol. 1, Instituto Enrique Flórez (CSIC), Madrid.

\footnotetext{
${ }^{69}$ Fernel 1582; Serrano Larráyoz 2014: 187-192, por ejemplo.

${ }^{70}$ Véase nota ${ }^{\circ} 4$.
} 
Arrizabalaga, J. (1996), “The Ideal Medical Practitioner en Counter-Reformation Castile: The Perception of the Converso Physician Henrique Jorge Henriques (c.1555-1622)”, in S. S. Kottek, L. García-Ballester (eds.), Medicine and Medical Ethics in Medieval and Early Modern Spain: An Intercultural Approach, Magnes Press, Jerusalem, 61-91.

Cabré, M. (2011), "Keeping Beauty Secrets in Early Modern Iberia”, in E. Leong, A. Rankin (eds.), Secrets and Knowledge in Medicine and Science, 1500-1800, Ashgate, Farnham-Burlington, 167-190.

Carmona, J. de (1590), Tractatus an astrologia sit medicis necessaria... ; Accessit insuper praxis subtilissima ad adcurarda cognoscendamq; pestilentiem apprime necessaria, eiusdem authoris, Franciscum Perez, Sevilla.

Cifuentes i Comamala, L. (2006, 2a ed.), La ciencia en català a l'Edat Mitjana i el Renaixement, Universitat de Barcelona-Universitat de les Illes Balears, BarcelonaPalma de Mallorca.

Cifuentes i Comamala, L. (2008), "La ciencia en vulgar y las élites laicas, de la Edad Media al Renacimiento”, in F. Serrano Larráyoz, [Juan Vallés] Regalo de la vida bumana, Vol. 2, Gobierno de Navarra-Österreichische Nationalbibliothek, Pamplona-Viena, 123-148.

Cotarelo Valledor, A. (1945-1946), El cardenal don Rodrigo de Castro y su fundación en Monforte de Lemos, 2 vols., Magisterio Español, Madrid.

Cruz Cruz, J. (1997), Dietética medieval. Apéndice con la versión castellana del "Régimen de salud» de Arnaldo de Vilanova, La Val de Onsera, Huesca.

Fernel, J. (1577), Vniuersa medicina, tribus et viginti libris absoluta ab ipso quidem authore ante obitum dilegenter recognita, Eं quatuor libris nunquam antè editis, ad praxim tamen perquam necessariis aucta; nunc autem studio $\mathcal{E}$ dilegentia Guil. Plantiij Cenomani postremùm elimata, $\mathcal{E}^{2}$ in librum Therapeutices septimum doctissimis scholiis illustrata, Iacobum Stoer, [s. 1.].

García Ballester, L. (2001), La búsqueda de la salud. Sanadores y enfermos en la España medieval, Península, Barcelona.

Gil-Sotres, P. (1996), "Introducción”, in L. García Ballester, M. R. McVaugh, P. GilSotres, J. A. Paniagua (eds.), [Arnaldi de Villanova] Regimen sanitatis ad regem Aragonum, in L. García Ballester, M. R. McVaugh, P. Gil-Sotres, J. A. Paniagua (eds.), Arnaldi de Villanova Opera Medica Omnia, Vol. X.1, Universitat de Barcelona-Fundació Noguera, Barcelona, 471-885.

Gutiérrez Rodilla, B. (2009), "La adecuación lingüística al destinatario en los textos médicos instructivos y de divulgación del Renacimiento castellano", Res Diachronicae 7: 37-46.

Houllier, J. (1571), Ad libros Galeni de compositione medicamentorum kata topus Periochae VIII, Carolum Macaeum, París.

Laín Entralgo, P. (1998, 3a ed.), La historia clínica. Historia y teoría del relato patográfico, Tricastela, Madrid.

Lobera de Ávila, L. (1996), Banquete de nobles caballeros, R \& B Ediciones, Donostia/ San Sebastián. 
López Piñero, J. Ma.; Calero, F. (1988), Los temas polémicos de la medicina renacentista: las «Controversias» (1556) de Francisco Vallés, Consejo Superior de Investigaciones Científicas, Madrid.

Madrid, Biblioteca Nacional de España, Manuscritos 3355, pp 301-313.

Madrid, Real Academia de la Historia, Papeles de Jesuitas tomo 9/3669, fol 334.

Madrid, Real Academia de la Historia, Papeles de Jesuitas tomo 9/3678, fol 145r

Mercuriale, G. (1590), De compositione medicamentorum. De morbis oculorum et aurium. Ipso praelegente olim Patauii diligenter excepti. Et nune primum a Michaele Columbo philosopho E' medico editi. Cum indicibus copiosissimis, Iuntas, Venecia.

Moreno Rodríguez, R. Ma . (1985-86), "Acerca de la cualidad del calor innato en las fiebres, según Galeno”, Dynamis. Acta Hispanica ad Medicinae Scientiarumque Historiam Illustrandam 5-6: 11-30.

Nicoud, M. (2007), Les régimes de santé au Moyen Âge: naissance et difusión d'une écriture médicale (XIII $-X V^{e}$ siècle), Vol. I, École Française de Rome, Rome.

Nicoud, M. (2010), "La dietética medievale: testi e lettori", Minerva 23: 15-34.

Nola, R. de (1999), Libro de guisados, La Val de Onsera, Huesca.

Núñez de Oria, F. (1585), Regimiento y aviso de sanidad: que trata de todos los géneros de alimentos y del regimiento della, Francisco del Canto-Pedro Landry-Ambrosio du Por, Medina del Campo.

Rodríguez, P. (1998), El Catecismo Romano ante Felipe II y la Inquisición Española, Rialp, Madrid.

Salas Merino, V. (2014), Tenencia, señorío y condado de Lemos, Visión Libros, Madrid.

Sánchez-Moscoso Hermida, A. (1982), "Concepto científico de nutrición en un texto médico del siglo XVI: "De regimine cibi atque potus”, de Enrique Jorge Enríques”, in América y la España del siglo XVI, Consejo Superior de Investigaciones Científicas-Instituto Fernández de Oviedo, Madrid, 219-231.

Serrano Larráyoz, F. (2014), "Prescripciones dietéticas para las élites rectoras del reino de Navarra durante la primera mitad del siglo XVI: los casos de Juan Rena y Juan de Alarcón", Dynamis. Acta Hispanica ad Medicinae Scientiarumque Historiam Illustrandam 34/1: 169-192.

Serrano Larráyoz, F. (2015), Léxico medico y farmacológico en lengua vulgar y latina de la documentación cortesana navarra (siglos $X I V-X V$ ), Pamiela, Arre-Pamplona.

Siriasi, N. G. (2003), "History, Antiquarianism, and Medicine: The Case of Girolamo Mercuriale", Journal of the History of Ideas 64/2: 231-251.

Solomon, M. (2010), Fictions of Well-Being: Sickly Readers and Vernacular Medical Writing in Late Medieval and Early Modern Spain, University of Pennsylvania Press, Philadelphia-Oxford. 


\section{Apéndice documental}

[Sevilla, 1583-1600]

Régimen de vida personalizado o «consilium» para el cardenal Rodrigo de Castro Madrid, BNE, Ms 3355: 301-313

pág 301/ El Illustrísimo cardenal de Castro se quexa de un ruido que siente en la cabeça, el qual siente a la continua de algunos días a esta parte, aunque es más al despertar del sueño i mucho menos después que entra el día.

Cuentan Eliano ${ }^{71}$ i otros istoriadores illustrísimos ${ }^{72}$ que estando Aristóteles enfermo dixo a un médico que sin tratar la causa de $\operatorname{su}^{73}$ enfermedad le vedava muchas cosas de su gusto i le mandava que hiziese otras de mucho desgusto:

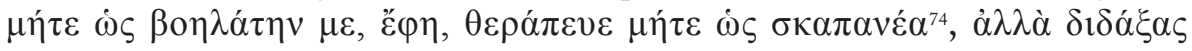

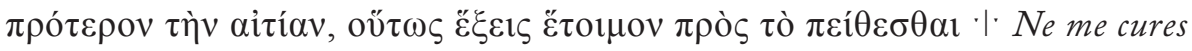
inquit ${ }^{75}$ ut bubulcum vel ut fossorem, sed prius causam edissere, sic enim facile me praeceptis tuis morigerum reddideris. Enseñándonos ${ }^{76}$ este filósofo con su dicho que ni el médico por su gusto ${ }^{77}$ a de quitar al enfermo ${ }^{78}$ nada sino porque la razón i causa del mal lo quita, ni el enfermo por gustoso ni desabrido que sea a de rehusar $\mathrm{el}^{79}$ dexar $\mathrm{i}$ admitir lo que la causa de la enfermedad pidiere que se dexe o tome.

Aviendo pues nosotros de quitar algunas cosas del regimiento de Vuestra Illustrísima i de añedir otras, que lo uno i lo otro podría causar disgusto, estamos obligados de satisfazer a la razón para que ella sea la que modere i tenga a raya los apetitos, sin que nosotros tengamos más parte en esto de proponer a Vuestra Illustrísima la essentia de lo que ${ }^{80}$ padece i las causas que lo hazen, para que ello mismo muestre el remedio que tiene. Para averiguar que sea $\mathrm{i}$ como se haga el ruido que uno siente dentro de la cabeça es menester saber de Aristóteles ${ }^{81}$ como se causa el oír, pues no es otra cosa esta ${ }^{82}$ indis- pág 302/ pusición sino un sonido que se oye sin que de fuera aya quien haga ni mueva tal sonido. El sonido dize Aristóteles se haze meneándose con violencia el

\footnotetext{
${ }^{71}$ Liber 9] Ms. margen izquierdo

72 illustrísimos] Ms. interlineado.

$\left.{ }^{73} \mathrm{mal}\right] \mathrm{Ms}$. tachado.

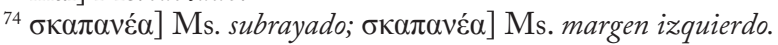

75 inquit] Ms. interlineado.

${ }^{76}$ Dándonos a entender] Ms. tachado; enseñándonos] Ms. interlineado.

${ }_{77}^{77}$ por su gusto] Ms. interlineado.

${ }_{78}^{78}$ por su gusto] Ms. tachado.

79 de] Ms. tachado.

${ }^{80}$ Vuestra Illustrísima] Ms. tachado.

${ }^{81}$ Liber 2, De anima, capitulum 8] Ms. margen izquierdo.

82 enfer] Ms. tachado.
} 
ayre exterior i óyesse cuando este ayre assí vehemente llega a entrarse por el oído del que le a de oir i le mueve el aire que naturalmente tenemos encerrado en el instrumento con que oímos, que consta de aquellos tres uessos que los anatomistas de nuestros tienpos an hallado ${ }^{83}$ que por el oficio que hacen los $\operatorname{dos}^{84}$ al uno llaman yunque i al otro martillo, i al tercero, por la semejança, le llaman estribo, i de unas telas i estos uessos se haze el que llaman tímpano o pandero que ${ }^{85}$ es uno de los grandes artificios que los onbres an hallado en la compostura del onbre ${ }^{86}$. Lo referido de Aristóteles dize ${ }^{87}$ : Ac illud quidem vim resonandi habet, quod aëra consunctum atque continuatum usque ad auditum impellere potest. Auditus autem est insitus quidam aër a natura qui quoniam ad aëra pertinet simulatque id quod extra patet pellitur, pellitur id etiam quod intus est ${ }^{88}$. I assí dixo muy bien que por medio deste aire que tenemos encerrado ${ }^{89} \mathrm{se}$ oye debaxo del agua como lo hacen los buzos cuando buscan por donde entra el agua al navío pegando el oído a la madera i escuchando a donde oyen ${ }^{90} \mathrm{el}$ sonido que el agua haze en la entrada para señalar i acudir allí a calafetear la nao. Queda pues de aquí que no puede aver sonido sin aire, ni oírse el tal sonido sin que este mismo aire llegue a menear el que tenemos insito de naturaleza metido ${ }^{91}$ en el instrumento del oír, de donde necessariamente se sigue que si averiguando el que oye el sonido que no es porque se mueva aire de fuera, que a de ser la causa el aire que se mueve dentro en la cabeça a que llamamos flatos o ventosedades. De donde queda provado que lo que haze ruido en la cabeça que es ${ }^{92}$ la indispusición que tratamos es ventosedad ${ }^{93}, \mathrm{i}$ aunque los autores médicos que trataron de tinnitu aurium ponen muchas causas por no aver ${ }^{94}$ buscado bien la que es immediata, todas ellas se an de reduzir a esta porque la causa que ponen de que no siente este ruido por ${ }^{95}$ tener grande agudeza en el oír está claro que no quita nuestra causa, pero dize que es verdad que con menos vapor o ventosedad que esta tal tenga sentirá

83 el uno semejan] Ms. tachado.

${ }^{84}$ los dos] Ms. interlineado.

${ }^{85}$ con el aire] Ms. tachado.

${ }^{86}$ que consta de aquellos tres uessos que los anatomistas de nuestros tienpos an hallado que por el oficio que hacen los dos al uno llaman yunque i al otro martillo, i al tercero, por la semejança, le llaman estribo, i de unas telas i estos uesos se haze el que llaman tímpano o pandero que es uno de los grandes artificios que los onbres an hallado en la compostura del onbre] Ms. margen izquierdo.

${ }^{87} \mathrm{i}$ así dixo] Ms. tachado; Lo referido de Aristóteles dize] Ms. interlineado.

${ }^{88}$ Sobre los comentarios referidos, Aristóteles, Acerca del alma, Gredos, Madrid, 2010: 71-73).

${ }^{89}$ que tenemos encerrado] Ms. interlineado.

${ }^{90}$ la entrada] Ms. tachado.

${ }^{91}$ metido] Ms. interlineado.

92 de] Ms. tachado.

${ }_{93}^{9}$ que] Ms. tachado.

${ }_{94}$ aver] Ms. interlineado.

95 de] Ms. tachado. 
lo que otro que sino fuesse de tan agudo oír no lo sentiría. Pero al fin más o menos ventosedad es lo que en este como en todos los demás es pág 303/ causa del ruido que siente en la cabeça, salvo sino fuesse tan grande la biveza de oído deste que el aire exterior que con su ordinario movimiento no causa sonido en otros $^{96}$ en él le hiziese de manera que sin ventosedad ni enfermedad sino solo tener exactíssimo oído le causase ruido perpetuo, que al fin viene a parar la causa que es mediata del açidente aunque no para la cura como después diremos ${ }^{97}$. Tanpoco se a de poner por causa inmediata la flaqueza por ver que ${ }^{98}$ los convalecientes de largas enfermedades $\mathrm{o}^{99}$ los que an tenido grandes evacuaciones se suelen quexar desto hasta que se esfuerçan i están del todo sanos i reparados, porque si iuzgan esta flaqueza en el oír antes será causa de que no perciban el ruido que oviere, como al contrario, la demasiada agudeza de oír es causa de que se perciba el movimiento del aire que sin ella no se percibiera. I si esta flaqueza la consideran en las facultades a manera ${ }^{100}$ que tengan débil la potencia natural, la vital i la animal, desta manera vienen a tener falta de calor natural i a hazer mal las coctiones i engendran flatos, los cuales son causa del ruido de la cabeça, $i$ al fin an de venir a parar a dar esta por causa del ruido, pues como tenemos averiguado es la immediata dél. I todas las otras que los autores traen no lo son hasta que hazen esta, i assí los que ponen por causa del tinnitu aurium umores crassos i viscosos no dizen bien pues estos harán obstrución con gravedad i no ruido en la cabeça hasta que dellos se vengan a levantar ventosedades que le causan. Lo qual pudieran aver aprendido de Galeno ${ }^{101}$ que declarando a Hippócrates quando refirió los acidentes que se causan en un enfermo por ponerle el médico al principio de la enfermedad ${ }^{102}$ en demasiada dieta i después antes del vigor dándole mucho a comer, entre otros dize Hippócrates: aures implentur sono, i declarando Galeno esto dixo: aures sonis implentur tum propter eos, qui a ventre sursum feruntur vapores, tum propter flatuosum spiritum, qui in capite ipso oritur, que es dezir lo que nosotros dexamos averiguado por vapor o ventosedad, que todo viene a ser una cosa. I el mismo Galeno, declarando otro lugar de Hippócrates ${ }^{103}$ en que dezía: si in ardente febre aurium sonitus cum caligine $e^{\text {pág 304/ }}$

${ }^{96}$ en otros] Ms. interlineado.

${ }^{97}$ salvo sino fuesse tan grande la biveza de oído deste, que el aire exterior que con su ordinario movimiento no causa sonido en otros en él le hiziese de manera que sin ventosedad ni enfermedad sino solo tener exactíssimo oído le causase ruido perpetuo, que al fin viene a parar la causa que es mediata del açidente aunque no para la cura como después diremos] Ms. margen superior e izquierdo.

98 en] Ms. tachado.

${ }^{99}$ en] Ms. tachado.

100 a manera] Ms. interlineado.

${ }^{101}$ I [=primo] De Victus ratione [in morbis] acutis, tractatus 44] Ms. margen izquierdo

102 de la enfermedad] Ms. margen izquierdo.

${ }^{103}$ I [=primo] Prorrheticorum, commentum I, tractatus 18] Ms. margen izquierdo. 
fuerit et cetera, dixo Galeno: ex ea vero quae capite redundat humiditate spiritus flatuosus procreatur: qua propter et aurium tinnitus fiunt. Pero para echar el sello a todo lo dicho enseñó Galeno esta indispusición i a curarla, aunque de pocos entendido ${ }^{104}$ o por mejor dezir de ninguno que yo sepa.

Liber 3. De pharmacorum secundum locos, cap. 1, fol. 144. D.E.F ${ }^{105}$. Sonitus in auribus quidam ex flatuoso spiritu generantur. Quidam ob exquisitam sensus audiendi subtilitatem fiunt, quemadmodum in oculis imaginarie suffusiones, propter vapores exore ventris exhalantes. De manera que aviendo reduzido todos los sonidos en los oídos a dos causas, la una dize es por ventosidades i la otra por exquisita biveza de oír que uno tenga, i para declarar que habla de ruido que no tiene causa en lo que el primero ${ }^{106}$ dize que es como los que parece que ven telarañas i no es de umor que corre a los ojos para hazer catarata sino vapor del estómago que sube a los ojos i se pone por delante de la niñeta ${ }^{107}$, i añade que conocer cuando el ruido viene de ventosedad o de demasiada biveza de oír no se puede luego en los principios averiguar con certidumbre. Pero que no por esso emos de començar a inquirirlo o curarlo $\sin \operatorname{arte}^{108}$, i enseña ${ }^{109}$ al que supiere bien conocer en virtud de que lo haze una arte de buscar ${ }^{110}$ la causa verdadera i immediata del ruido de la cabeça por las causas exteriores ${ }^{111}$ que la suele causar ${ }^{112}$, unas vezes se dize ${ }^{113}$ causa de frialdad i otras de ardor, otras vezes de un golpe que dieron a uno en la cabeça le queda ruido, otras vezes de tal o tal enfermedad que tuvo, otras de averse ahitado, otras averse enborrachado, otras de aver hecho fuerça para vomitar i otras vezes de se aver echado alguna medicina en el oído se le causó el ruido. Añada a esta invención el atender si se hizo de repente o poco a poco, si es continuado que sienpre siente el ruido o por intervalos. I al fin dize $^{114}$, con el tienpo i con la experiencia de usar algunas medicinas se viene a tener certidunbre de si es por ventosedades o por de- pág $305 /$ masiada biveza

${ }^{104}$ entendido] Ms. interlineado.

${ }^{105}$ Lege Hieronymus Mercurialis, Tractatus de aurium affectibus, capitulum 3, folium 57, facies 2. In (?) dubium tetigisse depraehendere non tamen consequntum] Ms. margen izquierdo.

${ }^{106}$ exterior] Ms. tachado; en lo que el primero] Ms. interlineado.

${ }^{107}$ pero] Ms. tachado.

108 como si buscase en que] Ms. interlineado y tachado; i enseña una de buscar] Ms. interlineado y tachado;

${ }^{109} \mathrm{i}$ enseña] Ms. interlineado; una de buscar] Ms. interlineado y tachado.

${ }^{110}$ al que supiere bien conocer en virtud de que lo haze una arte de buscar] Ms. margen izquierdo.

${ }^{111}$ al que supiere bien conocer en virtud de que lo haze ( \pm 2 : Ms. ilegible)] Ms. interlineado tachado.

112 de] Ms. tachado.

113 dize] Ms. interlineado.

114 dize] Ms. interlineado. 
de oído, i haze tanto caudal desta causa de ruido por ${ }^{115}$ la demasiada biveza de oír ${ }^{116}$ porque totalmente muda la cura, pues en todas las demás emos de acudir a quitar ventosedades $i$ las $\operatorname{cosas}^{117}$ que son causa ${ }^{118}$ dellas, i en esta como hizo Galeno i la razón lo pide no ai más cura que enbotar un poco la demasiada biveza de oír. I desta es de la que diximos arriba que sin aver ventosedades sino solo con el ordinario movimiento del aire es la biveza del oír tanta que le causa ruido, que deste movimiento del aire ${ }^{119}$ ordinario se entiende la respuesta de Anaxágoras quando preguntado cur interdiu minus audimus, respondió quoniam commotio aëris maior est unde et sonorum confusio.

Pues tenemos averiguado que lo que haze el ruido en la cabeça es ventosedad, pide el arte de curar por méthodo que averiguemos qué sea i ${ }^{120}$ cómo se engendra la ventosidad para que quitando sus causas preservemos i curemos desta indispusición. Lo que en vulgar español llamamos ventosidad llamó Galeno $\pi v \varepsilon \tilde{u} \mu \alpha$ $\varphi \sigma \sigma \tilde{\omega} \delta \varepsilon \varsigma$ i spitritus flatuosus, i no solamente dize se llama spiritu flatuoso pero tanbién se llama $\Phi v ́ \sigma \alpha$, que quiere decir flato, i este dize que es un spiritu craso i vaporoso, que en la sustancia no es tenue ni ethereo el modo como se engendra ${ }^{121}$. Enseñó Galeno ${ }^{122}$ maravillosamente con un exenplo de lo que passa en el mundo que es manifiesto a todos, que en tiempo de grandíssimos fríos los días son claros i assimismo en tienpo de días calurossímos no ay nieblas, pero fuera destos dos extremos acontece aver días nebulosos, i como la razón que ponen las filósofos desto es porque el calor levanta de la umedad el vapor i si es calidíssimo como lo va levantando lo disipa, i assí en días calidíssimos no puede aver nieblas i al contrario, en día frigidíssimo no ay calor para levan- pág 306/ tar vapor, i assí aunque por contraria razón vienen a ser los días frigidíssimos i los calidíssimos serenos sin nébula, de la misma manera raciocina el médico en el cuerpo umano que el que tuviere mucha falta de calor natural ${ }^{123}$ no engendrará ventosedades $\dot{i}^{124}$ ni el que tuviere fuerte calor natural, porque el uno no levantará vapores i el

${ }_{115}$ por] Ms. tachado; por] Ms. interlineado.

116 do] Ms. tachado.

117 causas] Ms. tachado; cosas] Ms. interlineado.

118 s] Ms. tachado.

${ }^{119}$ del aire] Ms. interlineado.

${ }^{120}$ que sea i] Ms. interlineado.

${ }^{121}$ Lo que en vulgar español llamamos ventosidad llamó Galeno $\pi v \varepsilon \tilde{u} \mu \alpha \varphi$ $\varphi \sigma \tilde{\omega} \delta \varepsilon \varsigma$ i spitritus flatuosus, i no solamente dize (le: Ms. tachado) se llama spiritu flatuoso pero tanbién se llama $\Phi v ́ \sigma \alpha$ (debería decir $\varphi \tilde{v} \sigma \alpha)$ que quiere decir flato, i este dize que es un spiritu craso (gruesso: Ms. tachado) i vaporoso, que en la sustancia no es tenue ni ethereo el modo como se engendra] Ms. margen superior e izquierdo; esto] Ms. tachado.

${ }_{122}$ Liber 3, De symptomatum causis, capitulum 2, folium 27. E.F.] Ms. margen izquierdo.

${ }^{123}$ natural] Ms. interlineado.

$\left.{ }^{124} \mathrm{el}\right]$ Ms. tachado. 
otro los consumirá. De donde se colige que el calor natural diminuto viene a engendrar ventosedades como causa efficiente, i aunque el médico no tiene necessidad para la cura del ruido de la cabeça de buscar la causa formal ni final de la ventosedad, tiene enpero forçosa obligación de inquirir la causa efficiente, como lo emos hecho, i la material ex qua et in qua se engendran las ventosedades. La materia de que se levantan las ventosedades es toda aquella que contiene en sí tal umedad que el calor la puede levantar i no gastar. I assí dixo Galeno: Quod autem ex crassioribus humoribus spiritus flatuosus oriatur, id antea audiuistiti25, i en otro lugar: quippe lenti omnes, crassique ${ }^{126}$ et frigidi bumores ab iis quae calfaciunt, nisi etiam valenter digerant, liquantur ac in flatum mutantur ${ }^{127}$, i en otra parte: Spiritus flatuosus generatur ex humoribus ${ }^{128}$ viscosis ac crassis per moderatam caliditatem ${ }^{129}$. Sabida la materia de que se engendran las ventosedades no $^{130}$ es de ${ }^{131}$ menor importancia para nuestro caso saber el lugar donde se engendran, i según ${ }^{132}$ el que averiguaremos busqu[e]mos el remedio, i para lo que importa al ruido de la cabeça ya Galeno ${ }^{133}$ lo especificó diziendo que o se hazen los tales flatos en la misma cabeça o suben del estómago $^{134}$. Averiguado que el ruido de la cabeça tiene por su causa immediata ventosedad i que la ventosedad se causa de calor natural diminuto ${ }^{135}$, pues el calor natural pág $307 /$ puede padecer esto o por falta essencial, que aviéndose gastado por edad o por otra causa que le oviesse consumido el úmido radical, que es su pábulo de que se sustenta, sin que pudiesse recuperarse de manera que bolviese al ser de cuando hazía los officios perfectamente o puede estar diminuto respeto de la carga que los excrementos hacen en el sugeto, bien se ve que cuando fuere lo primero que no puede aver reparo, pero siendo lo segundo es fácil de dizir el que pide aunque muy dificultoso de executar pues pide evacuación de los excrementos que redundan i tal regimiento que no se engendren más de los que el mismo calor natural pudiere expeler.

Llegando pues a lo particular de nuestro caso, aunque se podía temer que la diminución de calor natural que arguye este acidente fuesse en Vuestra

${ }^{125} \mathrm{I}$ [=primo] Prorrbeticorum commentum I, tractatus ultimus.

${ }^{126}$ succi] Ms. tachado.

${ }^{127}$ Liber 3, Methodus medendi, capitulum ultimum] Ms. margen izquierdo.

128 in] Ms. margen izquierdo.

${ }^{129}$ Liber IX, De compositione pharmacorum secundum locos, capitulum 9] Ms. margen izquierdo; itus flatus] Ms. margen izquierdo tachado.

130 no] Ms. interlineado.

131 la] Ms. tachado.

132 para que conforme] Ms. tachado; i según] Ms. interlineado.

1332 [=secundo] De Victus ratione in morbis acutis, tractatus 44 antecitato] Ms. margen izquierdo.

${ }^{134}$ i assí] Ms. tachado.

135 llegando a lo particular de nuestro caso] Ms. tachado. 
Illustrísima la primera que dexamos dicho que no se puede reparar por las señales que se ven en las demás actiones, colegimos no ser la falta que se muestra en esto sino la que llaman los médicos per aggravationem, que es la segunda que arriba diximos, lo qual se prueva por el vigor que muestra en Vuestra Illustrísima el pulso i lo que puede el estómago i hígado con todas sus venas, como lo muestran los excrementos del vientre i urinas, i lo que sufre de trabajo la cabeça de Vuestra Illustrísima con la agilidad de los movimientos que Vuestra Illustrísima tiene, que todo ello muestra no ser esta falta per essentiam en el calor natural sino per aggravationem ${ }^{136}$, i que assí estará en mano de Vuestra Illustrísima el repararla, aunque es menester tienpo para la averiguación desto i assí perseverancia de parte de Vuestra Illustrísima en el regimiento.

Resta por averiguar si los flatos que causan en Vuestra Illustrísima este ruido si se engendran en la cabeça o son vapores que suben del estómago. I para pensar que no se engendran en la cabeça haze mucha probabilidad saber que Vuestra Illustrísima no tiene en ella ${ }^{\text {pág } 308 /}$ dolor ni pesadumbre ${ }^{137}$ i que tiene los sentidos, assí exteriores ${ }^{138}$ como interiores, con toda vivacidad, sin que por razón de la edad se eche de ver falta en ellos, i que la vigilia i sueño tienen su devida moderación, que arguye todo estar la cabeça con su tenplança natural i buen calor natural, que es el instrumento destas operaciones.

Por otra parte haze fuerça de creer que se engendren en la cabeça $a^{139}$ algunas destas ventosedades que son causa del ruido, pues si fueran enbiadas del estómago no fuera continuo el ruido, como es la señal que pone Galeno ${ }^{140}$ para conocer quando la enfermedad que está en una parte es por comunicación de otra ${ }^{141}$. Lo que podemos colegir de la relación que Vuestra Illustrísima nos hizo es que algo destas ventosedades se engendran en la cabeça, pues nunca se quitan del todo levantadas de algunos excrementos que no se repurgan bien por sus emunitorios, pero que tanbién es buena parte dellas comunicadas de los vapores que suben del estómago, i assí nos dezía Vuestra Illustrísima que sentía más el ruido al despertar del sueño i mucho menos después que entrava el día; que es señal de no se aver evaporado lo que con el sueño a subido que después con la vigilia i las operaciones que se hazen en él ${ }^{142}$ se disipa.

\footnotetext{
${ }^{136}$ como queda dicho] Ms. tachado.

${ }^{137}$ gravedad] Ms. tachado; pesadumbre] Ms. interlineado.

${ }_{138} 2$ [=secundo] $A d G(a$ : Ms. tachado)lauconem, capitulum 6] Ms. margen superior.

139 en la cabeça] Ms. margen interlineado.

${ }^{140}$ Liber 2, De locis affectibus, capitulum ultimus] Ms. margen izquierdo.

${ }^{141}$ i assí] Ms. tachado.

142 i las operaciones que se hazen en el] Ms. interlineado.
} 
$\mathrm{De}^{143}$ lo dicho se colige necessariamente que para curar este ruido emos de tener muy particular quenta con el estómago i con la cabeça, i como es precepto en Medicina no se puede curar la parte sin que primero se cure el todo, i añidió Platón ${ }^{144}$ a esto que no se puede curar el todo sino se cura primero el alma, entendiendo por la cura del alma que tenga moderados apetitos i particularmente ${ }^{145}$ temperantia.

Esto supuesto será necessario que el regimiento de comida i bevida pág ${ }^{309 /}$ sea de ordinario en calidad de buen mantenimiento tenplado, que tenga buen modo de sustancia, ni gruesso, ni viscoso, ni aguanoso, i assí quedan excluidas las carnes de vaca, puerco ${ }^{146}$, toda venazón, javalín, manjar blanco, todos manjares de pasta i enpanadas i cecinas ${ }^{147}$. Permítense gallinas, pollos, capones, perdizes, gaçapos, cabrito, carnero i ternera. Védanse en este regimiento todos los pescados. Puédense comer alguna vez azedías, lenguados, moxarras i truchas, todo esto se entiende fresco, cozido in sure albo i comido caliente, i de ninguna manera en pan porque aunque son malas todas enpanadas son peores las de pescado.

Frutas las de invierno se pueden comer como no sea melón. Las de verano sería bien no provarlas pero porque parece mucho rigor se pueden permitir, por principio ${ }^{148}$, alguna buena ciruela o pocas uvas después de aver estado colgadas algunos días ${ }^{149}$, buena pera o membrillo por postre.

A de ser regla general en las ${ }^{150}$ comidas i cenas usar de pocos manjares i simples, que no sean guisados.

Dévese repartir la cantidad ${ }^{151}$ del mantenimiento de manera que a la comida sea lo principal i a las noches muy poco $^{152}$ i que no sea ${ }^{153}$ carne ni pescado lo que se cenare.

\footnotetext{
143 todo] Ms. tachado.

${ }^{144}$ In Charmide] Ms. margen izquierdo.

${ }^{145}$ moderados apetitos i particularmente] Ms. interlineado.

146 ciervo] Ms. tachado.

147 i cecinas] Ms. interlineado.

148 por principio] Ms. interlineado.

149 por principio] Ms. interlineado y tachado.

150 sus] Ms. tachado; las] Ms. interlineado.

151 la cantidad] Ms. interlineado.

152 de suerte] Ms. interlineado y tachado; de manera] Ms. interlineado y tachado.

153 abe ser] Ms. tachado.
} 
pág 310/ La bevida ordinaria será vino ligero que con poca agua no tenga fuerça de vino, i que no sean vinos desta tierra por el yesso que unos tienen $\mathrm{i}$ otros el mosto que les echan. El vino de Ciudad Real es el que se puede tener por mejor. El agua la mejor desta tierra es la de la Fuente del Algarrovo en el invierno. Sería muy conveniente cozerla con un poco de raíz de la China o con canela, i desta agua se podría usar para aguar el vino, i algunas vezes, principalmente a las cenas, beverla sin vino. Podríase cozer con media onça de la China en dos açumbres de agua hasta menguar medio açumbre ${ }^{154}$. I haciendo este cozimiento con tres açumbres de agua i media onça de China que coziese hasta menguar los dos se podría tomar cada mañana ocho onças, bien caliente, i procurar de dormir con ella haziendo esto por ocho días después de averse evacuado con las píldoras. No se a de bever tan frío como se puede a quien enfría con nieve sino fresco ${ }^{155}$. Entre día no conviene bever i en las comidas i cenas la menos cantidad que fuere possible.

El exercicio es importantíssimo para esta indispusición i para preservarse de otras muchas, pero a de ser con las condiciones que la Medicina manda, las quales son que a de ser en ayunas porque después de comer es causa de muchos males, i aún manda Galeno que para que el exercicio no haga mal que estén hechas la digestión del estómago, hígado i venas ${ }^{156}$, i después de aver expelido los excrementos de vientre i bexiga, començando moderadamente i creciendo poco a poco i acabando como se començó, teniendo cuenta con que llegue $\mathrm{a}^{157}$ mudar el aliento que se pág ${ }^{311 /}$ coge de vez que se a entrado en calor pero que no se llegue a cansarse. A de ser en ayre limpio de nieblas i de toda umidad i guardarse de ayres rezios i delgados que puedan penetrar el sugeto. I si fuere en el campo i en ocupación de contento, que no sea ir a hazer exercicio por solo la salud, es más provechoso; puédese hazer a cavallo o en litera i algunas vezes a pie. I porque en invierno ai días que no se puede salir a hazer exercicio, se suplirá esto con que a la mañana antes de levantar se hagan unas fricaciones de todo el cuerpo con lienço algo asperillo, i no recibiendo Vuestra Illustrísima pesadumbre se podría untar después de las fricaciones con azeite de almendras dulces, cosa que quedase enbevida en las

${ }^{154}$ I haziendo (echando] Ms. tachado) este cozimiento con tres açumbres de agua i media onça de China que coziese hasta menguar (las] Ms. tachado) los dos (mitad] Ms. tachado e interlineado) se podría tomar cada mañana ocho onças bien caliente i procurar de dormir con ella haziendo esto por ocho días después de averse evacuado con las píldoras (ocho onças bien calientes i procurar de dormir con ella] Ms. tachado)] Ms. margen izquierdo.

155 i aguándolo frío con lo caliente] Ms. tachado.

${ }^{156}$ porque después de comer es causa de muchos males i (así] Ms. tachado) aun manda Galeno que, para que el exercicio no haga mal que estén hechas la digestión del estómago, hígado i venas] Ms. margen izquierdo.

157 se] Ms. tachado; llegue a] Ms. interlineado. 
carnes, que es muy alabado, i como tal lo usava Paulo Tercio, que fue muy atento a la conservación de su salud, i en todas las comidas que avía de entrar azeite ussava deste de almendras dulces.

Como se veda el exercicio después de comer por muy dañoso assí lo es i en alguna manera más el leer o escrivir, tratar de negocios de entendimiento después de comer a lo menos ${ }^{158}$ por cuatro oras, $i$ aunque sea a oras convenientes daña mucho para enflaquecer la cabeça ${ }^{159}$ la mucha atención continuada i assí conviene evitarlo. I de lo dicho se sigue que Vuestra Illustrísima no deve rezar las oras después de cenar sino antes.

En lo del sueño es necessaríssimo andar concertado de manera que las oras que por experiencia tiene pág 312/ Vuestra Illustrísima que le son necessarias no se dexen por otra ninguna ocupación, ni será bien convienente ${ }^{160}$ postponer la ora del acostar ni anticipar la del levantar por ningún respeto que no inporte más que la salud ${ }^{161}$. El sueno (sic) de entre día no es bueno para Vuestra Illustrísima sino fuesse forçado de no aver dormido bastante ante la noche.

E1 hazer cámara cada día es de grande importancia para descargar la cabeça. Esto se adquiere con el uso de provar el servicio a la mañana i al acostar, i entretenerse en la expulssión de flatos i provocar a naturaleza a que tome esta costumbre. I no bastando esto i andando estreñido es muy apropósito recebir melezina de solo azeite común $\mathrm{o}^{162}$ hervido con mançanilla.

I si todo el regimiento que está puesto no bastare entra la parte de medicina que se aprovecha de medicamentos. I principalmente para curar el afecto presente del ruido de la cabeça conviene pues se a de llegar a evacuaciones de la parte. Evacuar primero el todo, para lo qual nos parece convinientissimo el uso de massa de píldoras de almáciga de la recepta de Fernelio, usando dellas aora para averse de hazer las demás cosas por una vez tomando peso de un real, pero después interpoladamente, conforme a la dispusición i a lo que las píldoras obraren se usará de un escrúpulo ${ }^{163}$, más o menos, conforme

\footnotetext{
158 a lo menos] Ms. interlineado.

${ }^{159}$ la (mucha] Ms. interlineado) atención continuada para enflaquecer la cabeza] Ms. Mediante las lineas indica el orden correcto de la frase, es una alteración en el orden de la misma.

160 convienente] Ms. interlineado.

${ }^{161}$ que no inporte más que la salud] Ms. interlineado.

162 o] Ms. interlineado.

163 o] Ms. tachado.
} 
a la necessidad, i obra que hiziere anse de tomar a las onze antes de dormir, aviendo cenado tenprano i menos que lo ordinario.

Después de purgado a de usar Vuestra Illustrísima ${ }^{164}$ cada mañana un rato de peinar i fregar la cabeza con algún lienço áspero i des- pág ${ }^{313 /}$ pues tomar algo que traer en la boca para desflemar, que será algún grano de almaciga, i procurar de que los oídos anden limpios de los excrementos i que por las narizes salgan los que desen venir por allí, i para esto es bueno usar de alguna aguamiel sorvida por las narizes ${ }^{165}$.

Supuesta la evacuación del todo i de la cabeça restan los remedios particulares que deshazen la ventosedad que es causa del ruido, a lo qual socorren los autores con remedios fuertes echados dentro del oído, de lo qual a nosotros nos parece que en ninguna manera deve Vuestra Illustrísima usar ${ }^{166}$ por el peligro que tienen de ensordecer semejantes medicinas ${ }^{167}$ no estando las evacuaciones hechas como convienen ni se pudiendo hacer ${ }^{168}$. Pero es cosa sigura tomar algún baho de cozimiento hecho en vinagre de yervas para el propósito, como son mançanilla, ruda, eneldo, cantuesso, hinojo, cominos ${ }^{169} \mathrm{i}$ anís, tomando el vapor por un cañuto metido en el oído i en la vasija que estuviesse este cozimiento ${ }^{170}$, i abrigando bien el oído con algodones que tuviesen algalia para que por ellos entre el vapor de manera que con su calor no dé pena. Después de tomado este vapor conviene tapar el oído con algodones con almizcle, mojados en agua ardiente, pág ${ }^{314 /}$ o usar de los saquillos de ciprés que Vuestra Illustrísima suele usar.

${ }^{164}$ Vuestra Illustrísima] Ms. interlineado.

165 i para mover estornudo mirar hazia el Sol] Ms. tachado.

${ }^{166}$ Lege Holerii, Liber 3, Periochae, folium 21] Ms. margen izquierdo.

167 de] Ms. tachado; por el peligro que tienen de ensordecer semejantes medicinas] Ms. interlineado.

$168 \mathrm{i}$ usando de semejantes medicinas] Ms. tachado.

${ }^{169}$ cominos] Ms. interlineado.

170 el vapor] Ms. tachado. 